\title{
A SOCIALIZAÇÃO E A EDUCAÇÃO INFANTIL - UM ENSAIO
}

\author{
SOCIALIZATION AND EARLY CHILDHOOD EDUCATION - AN ESSAY
}

L'SOCIALISATION ET EDUCATION DES ENFANTS - UN ESSAI

\author{
Sandro Vinicius Sales dos Santos \\ Doutor em Educação pela Universidade Federal de Minas Gerais. Docente da Faculdade \\ Interdisciplinar em Humanidades da Universidade Federal dos Vales do \\ Jequitinhonha e Mucuri - FIH/UFVJM - Diamantina, Minas Gerais, Brasil \\ sandrovssantos@gmail.com
}

\begin{abstract}
Resumo: Este: ensaio analisa os alcances das teorias sociológicas clássicas que discorreram sobre o conceito de socialização. A perspectiva funcionalista de Durkheim e a Sociologia do conhecimento de Berguer e Luckman são revisitadas a partir da emergência, no contexto brasileiro, das instituições de Educação Infantil. Tal empreendimento é realizado à luz de teorizações que compreendem a socialização como um processo mais interativo do que reprodutivo. $\mathrm{O}$ argumento defendido é o de que, na atualidade, as noções clássicas da socialização se mostram insuficientes em função das novas configurações legais da Educação Infantil brasileira. Tal legislação reconhece creches e pré-escolas como direito das crianças, que passam a ser concebidas como atores sociais ativos na própria socialização.
\end{abstract}

Palavras-chave: Socialização. Educação Infantil. Sociologia clássica.

Abstract: This: essay analyzes the scope of classical sociological theories that discussed the concept of socialization. Durkheim's functionalist perspective and Berguer and Luckman's Sociology of knowledge are revisited from the emergence, in the Brazilian context, of Early Childhood Education institutions. Such a task is performed in the light of theories that understand socialization as a process that is more interactive than reproductive. The argument defended is that, today, the classic notions of socialization are insufficient due to the new legal configurations of Brazilian Early Childhood Education. Such legislation recognizes nurseries and preschools as children's rights, which are now conceived as active social actors in their own socialization.

keywords: Socialization. Early Childhood Education. Classical Sociology.

Résumé: Cet essai analyse la portée des théories sociologiques classiques qui ont discuté le concept de la socialisation. La perspective fonctionnaliste de Durkheim et la sociologie de la connaissance de Berger et de Luckmann y sont revisitées à partir de l'émergence, dans le contexte brésilien, de l'école maternelle. On propose cette entreprise à la lumière des théories qui comprennent la socialisation comme un processus plus interactif que reproductif. En fonction des nouvelles configurations juridiques de l'éducation infantile brésilienne, reconnue comme un droit des enfants (et de leurs familles), on pense que les notions classiques de socialisation ne sont plus suffisantes. Ces législation reconnaît les crèches et les écoles maternelles comme des droits de l'enfant, qui sont désormais conçus comme des acteurs sociaux actifs dans leur propre socialisation.

Mots-clés: Socialisation. Education infantile. Sociologie classique.

Para citar - (ABNT NBR 6023:2018)

SANTOS, Sandro Vinicius Sales dos. A socialização e a educação infantil - um ensaio. Eccos Revista Cientifica, São Paulo, n. 52, p. 1-18, e10621, jan./mar. 2020. Disponível em: https://doi.org/10.5585/eccos.n52.10621. 


\title{
Introdução
}

\author{
Por que você é Flamengo e meu pai Botafogo? \\ O que significa "Impávido Colosso"? \\ Por que os ossos doem enquanto a gente dorme? \\ Por que os dentes caem? \\ Por onde os filhos saem? \\ Paula Toller (OITO anos, 1998, n.p.)
}

O que faz uma criança quando interpela o mundo? Irrita a alguns; a outros, entretém. Há, ainda, aqueles que ignoram a indagação, quiçá desprestigiam a própria criança. Entretanto, mais do que projetar dúvidas, ao problematizar o mundo, a criança interroga a nós (adultos), questionando nossas instituições, nossas certezas e nossos saberes. Por serem históricos, culturais e cientificamente instituídos, tais saberes se conformam como verdades sobre as crianças, sobre a infância e sobre a educação que nossa racionalidade fundou, sem, contudo, perguntar-lhes sobre suas vidas, sobre suas experiências, seus desejos e seus anseios.

O conjunto de questões presentes na epígrafe anterior demonstra a capacidade de as crianças engajarem-se nos processos de socialização que vivenciam cotidianamente, revelando, de certo modo, importantes nuances da exposição que será empreendida ao longo deste ensaio ${ }^{1}$. O enredo da canção "Oito Anos" - uma das faixas do álbum solo de Paula Toller, lançado em 1998 - é composto por uma série de perguntas feitas, por seu filho Gabriel, por vezes, de modo direto; outras, de modo inocente, mas, sobretudo, elaboradas com a perspicácia de quem, ao interrogar o mundo, evidencia o desejo singular de compreendê-lo, demonstrando, outrossim, a capacidade de desenvolvimento das crianças.

Mais do que reveladora de como as crianças interrogam o mundo, uma análise mais refinada dos versos da epígrafe elucida outra compreensão - nem sempre difundida nos meios acadêmicos - sobre os modos ativos e interativos com os quais as crianças confrontam os diferentes processos de socialização que vivenciam. Como se trata de uma música muito conhecida nas instituições de Educação Infantil, principalmente naquelas que se preocupam em apresentar belas canções às crianças e aos bebês - seus versos podem nos conduzir no processo de reestruturação do conceito de socialização. Tal exercício pode, inclusive, sensibilizar profissionais de creches e pré-escolas no que concerne ao reconhecimento das capacidades de produção simbólica das crianças, colaborando, igualmente, para a organização dos processos educacionais e das práticas de cuidados a elas destinadas.

Tal tarefa, contudo, necessita ser realizada com cautela, uma vez que a inserção das crianças em contextos coletivos de cuidados e de educação é um fenômeno social recente, particularmente visível na realidade brasileira a partir da década de 1970, mas que se 
institucionaliza, sobretudo, ao final da década de 1990. Diante disso, este ensaio busca refletir sobre como as teorias da socialização, produzidas no âmbito da Sociologia clássica, necessitam ser revistas, na atualidade, em função da emergência das instituições de Educação Infantil.

Importa destacar, no entanto, que a Sociologia clássica é aqui tomada em uma acepção muito particular. François Dubet (1996), sociólogo francês que tem objetivado compreender os sentidos que os indivíduos atribuem à experiência social, define a Sociologia clássica como um conjunto de ideias e de representações que atravessam diversas tradições de pesquisa. Para ele, a Sociologia clássica não é uma corrente nem tão menos uma escola de pensamento sociológico. Ela apenas congrega um conjunto de "[...] proposições simples por tanto tempo compartilhadas que acabam por adquirir um caráter “clássico"” (DUBET, 1996, p. 22).

Nesse sentido, não se propõe, aqui, uma extensa revisão do conceito de socialização ao longo da história do pensamento sociológico, tampouco o estabelecimento de um quadro comparativo no qual distintas tradições teóricas são confrontadas no que concerne ao entendimento desse conceito. $\mathrm{O}$ que se propõe é uma reflexão sobre a socialização em teorias consideradas "clássicas", uma vez que algumas tradições sociológicas abordaram as crianças de modo secundário nos estudos sobre as instituições que, historicamente, se ocuparam de sua educação, mais precisamente a família e a escola, excluindo, desse modo, meninos e meninas do pensamento social. Esse empreendimento é realizado à luz da incorporação da Educação Infantil aos quadros teóricos (e sociopolíticos) do campo educacional.

A inserção de creches e de pré-escolas aos sistemas de ensino configura-se como um avanço das políticas públicas para a infância, pois progressivamente tem possibilitado a superação de representações anteriormente presentes no imaginário coletivo de nosso país, que viam as crianças de até seis anos como sujeitos passivos aos processos de socialização. De igual modo, concebiam sua educação como uma tarefa simplesmente assistencial e não como um direito de toda a população com idade anterior aos seis anos (VIEIRA, 1986; CURY, 1998; SILVA, 2008).

Nesse processo, alguns fatores articularam-se e, paulatinamente, auxiliaram na compreensão da criança como sujeito de direitos (que é, simultaneamente, produto e produtora de cultura) e de como ocorre sua educação em contextos coletivos. Em primeiro lugar, do ponto de vista das políticas públicas, a inserção da Educação Infantil como primeira etapa da Educação Básica tem possibilitado uma melhor compreensão do que as crianças realizam em contextos educacionais organizados por pessoas diferentes dos adultos do meio familiar e cujas práticas de educação e de cuidados encontram-se repletas de intencionalidades pedagógicas. 
Em segundo lugar, torna-se necessário compreender um conjunto de transformações ocorridas no plano acadêmico-científico e que incidem sobre os modos de conceber as crianças na contemporaneidade. Esse fato deve-se a um aumento significativo de estudos de cunho sociológico $^{1}$ que as tomam como seres capazes de participar de diversificados processos de socialização, fenômeno também visível em muitos outros países do mundo (SANTOS, 2014, 2015).

O terceiro fator relaciona-se à compreensão das instituições de Educação Infantil como espaços privilegiados de socialização para as crianças que veem, nas brincadeiras e nas diferentes interações que elas vivenciam (entre si, na relação com os adultos e com diferentes elementos presentes no mundo físico e social), possibilidades pedagógicas de ampliação do desenvolvimento infantil (BRASIL, 2009), tal como Gabriel, o eu-lírico da canção Oito anos de Paula Toller (1998), faz ao interrogar-se (e ao interrogar-nos) sobre o mundo.

Nessa direção, do ponto de vista legal, presencia-se a emergência de uma nova compreensão sobre a função social de creches e pré-escolas, agora organizadas segundo uma partilha de responsabilidades entre o Estado e as famílias, saindo do campo da assistência social e dirigindo-se para o campo da educação, processo inaugurado com a Constituição Federal de 1988 (BRASIL, 1988) e ratificado pela Lei de Diretrizes e Bases da Educação Nacional (LDBEN) No 9.394, de 20 de dezembro de 1996 (BRASIL, 1996).

$\mathrm{O}$ argumento aqui defendido é o de que a inserção das crianças cada vez mais cedo em instituições públicas que oferecem cuidados e educação, organizados em uma perspectiva distinta daquela realizada no ambiente familiar, põe à prova algumas teorias clássicas da socialização. O fundamento de tal assertiva sustenta-se no fato de que, na atualidade, aumenta a compreensão de estudiosos de diversas áreas do pensamento educacional acerca de que esse processo deve ser pensado, cada vez mais, a partir de uma pluralidade de formas complexas e, por vezes, multifacetadas de socialização de meninos e de meninas.

A socialização é uma palavra presente, já há algum tempo, no vocabulário de professores, de sociólogos, de psicólogos e de antropólogos, que, comumente, designa o processo de integração dos indivíduos ao corpo social. Durante muito tempo, ela foi pensada como um processo único e unilateral, pois era a sociedade quem conformava a subjetividade dos indivíduos, alinhando-a com a objetividade do sistema social. Contudo, com a percepção, nos tempos atuais, da heterogeneidade de princípios constitutivos e reguladores da vida social, o conceito de socialização passa a ser concebido sob uma dupla afirmação. Conforme sugerem Dubet e Martuccelli (1997): 
A socialização designa o duplo movimento pelo qual uma sociedade se dota de atores capazes de assegurar sua integração e de indivíduos, sujeitos suscetíveis de produzir uma ação autônoma. De imediato, a socialização é definida por uma tensão situada no centro de diversos debates sociológicos, mobilizando, de uma só vez, representações do ator e representações do sistema social. (DUBET; MARTUCCELLI, 1997, p. 241).

Para esses autores, cada uma das dimensões conceituais da socialização pressupõe a distinção de dois grandes conjuntos de teorias: de um lado, um grupo concebe a socialização como uma forma de interiorização de normas e de valores culturais, garantindo certo nível de reciprocidade entre a objetividade do sistema e a subjetividade dos atores. De outro lado, um segundo grupo que opera com a questão da atividade dos indivíduos, do distanciamento, isto é, da separação entre o ator e o sistema; vê a socialização como processo ativo e reflexivo pelo qual o sujeito toma uma posição crítica em relação à sociedade (DUBET, 1996; DUBET; MARTUCCELLI, 1997). Desse modo, esses autores seguem pontuando que "[...] podemos admitir grosseiramente que o primeiro conjunto de teorias se inscreve na imagem clássica da modernidade, enquanto que o segundo, mais sensível à heterogeneidade cultural e social, procede de uma concepção 'pós-moderna' do indivíduo" (DUBET; MARTUCCELLI, 1997, p. 241).

No âmbito do conhecimento sociológico, essa tensão entre diferentes posicionamentos teóricos em relação à noção de socialização é posta à prova a partir da década de 1970 do século passado com a reformulação epistemológica das ciências sociais - proporcionada pelo movimento comumente conhecido como "o retorno do ator". A partir de então, o conceito de socialização - construído no bojo das teorias sociológicas clássicas - tem sido severamente criticado por diversos/as autores/as. Tal crítica vem sendo realizada por pesquisadores/as de inúmeras subdisciplinas das Ciências Sociais, tais como: da Sociologia da Educação (DUBET, 1996; DUBET; MARTUCCELLI, 1997; ABRANTES, 2011; dentre outros/as); da Sociologia da Família (MONTANDON, 2001; SINGLY, 2007); dos Estudos da Infância (SIROTA, 2001; JENKS, 2002; PLAISANCE, 2003, 2005; SARMENTO, 2008; MARCHI, 2009; CORSARO, 1997; dentre outros/as); da Economia (QVORTRUP, 2011); da Sociologia das Profissões (DUBAR, 2005), dentre outros campos teóricos.

No caso das crianças de até seis anos, as configurações contemporâneas da socialização - que se alteram tanto em função das transformações dos modos de vida dos adultos quanto pelo refinamento das formas de conceber a capacidade de ação das crianças (MOLLOBOUVIER, 2005) - encontram nas instituições de Educação Infantil um fecundo terreno de investigação. A emergência recente de tais instituições permite construir questões que interpelam noções historicamente construídas sobre os processos de socialização, seja 
problematizando a perspectiva clássica da integração das crianças ao corpo social (que tem Emille Durkheim (2007 [1895]; 2011 [1922]) como precursor), seja apontando a fragilidade da relação entre socialização primária e socialização secundária (presente na Sociologia do Conhecimento de Berger e Luckman (2004 [1975])) - autores cujas produções teóricas sobre a socialização tornaram-se clássicas. A alternativa a essas questões é elaborada à luz de perspectivas sobre a socialização que a percebem como um processo multifacetado, mais interativo e interpretativo do que uma mera assimilação dos indivíduos pela sociedade.

\section{Durkheim e a gênese da ideia "clássica" de socialização}

[...] se as crianças aprendessem somente aquilo que lhes é ensinado... nossa espécie já deveria ter acabado há muito tempo Marx Wartofski (1981, p. 202, tradução nossa).

Durante muitas décadas, a socialização foi, sociologicamente, compreendida como uma gradativa inclusão dos sujeitos na sociedade, uma vez que nomeava o amplo processo que institui, em outras palavras, que transforma os seres humanos em seres sociais. Essa visão um tanto objetiva da noção de socialização e que perdura em algumas tradições de investigação sociológica até os dias atuais - tem suas raízes no pensamento do sociólogo francês Emile Durkheim. Esse autor (um dos pais fundadores da Sociologia francesa e um dos primeiros cientistas sociais a debruçar-se sobre os métodos desse campo de produção de conhecimento) desenvolveu uma teoria da socialização que buscava estabelecer reciprocidade entre a objetividade do sistema e a subjetividade dos atores (DUBET, 1996; DUBET; MARTUCCELLI, 1997).

Durkheim analisou a educação por meio de seus aspectos constitutivos e a partir de uma compreensão dos processos de socialização como fato social. Ele concebeu o fato social como as "[...] maneiras de agir, de pensar e de sentir, exteriores ao indivíduo, e que são dotadas de um poder de coerção em virtude do qual esses fatos se impõem a ele" (DURKHEIM, 2007 [1895], p. 3). Para o autor, o fato social constitui toda maneira de fazer, cuja fixidez possua maior ou menor intensidade, capaz de "[...] exercer sobre o indivíduo uma coerção exterior; ou ainda, toda maneira de fazer que é geral na extensão de uma sociedade dada e, ao mesmo tempo, possui uma existência própria, independente de suas manifestações individuais" (DURKHEIM, 2007 [1895], p. 3, grifos do autor).

Como forma de comprovar a dimensão objetiva (evidenciada pelo caráter externo) desses modos de agir, de pensar ou de sentir, Durkheim (2007) argumentou que tais condutas têm de ser internalizadas por meio de um extenso processo educativo. Na perspectiva de Durkheim, 
“[...] como todo fato social, a educação é então concebida na sua força de imposição, de coerção (em termos de ideias, sentimentos e práticas), que se exerce sobre todo indivíduo no cerne de uma sociedade" (PLAISANCE, 2005, p. 224). Desse ponto de vista, Durkheim (2011 [1922], p. 98) compreendia que “[...] a educação é uma coisa eminentemente social, tanto por suas origens tanto por suas funções e que, logo, a Pedagogia depende mais da Sociologia do que qualquer outra ciência". Para ele, suplantar o ser individual formando o ser social em cada um de nós é a finalidade da educação.

A partir dessa compreensão - na qual os processos pedagógicos são concebidos como fato social -, Durkheim acreditava que a educação (como forma prática dos processos de socialização) se impunha sobre as novas gerações ao mesmo tempo que lhes impunha a sociedade. Nas palavras de Durkheim (2007 [1895], p. 6), “[...] quando se observam os fatos tais como são e tais como sempre foram, salta aos olhos que toda educação consiste num esforço contínuo para impor à criança maneiras de ver, de sentir e de agir às quais ela não teria chegado espontaneamente".

O autor explica que nós adultos coagimos as crianças a comer, a beber, a dormir regularmente nos mesmos horários, forçando-as “[...] à limpeza, à calma, à obediência; mais tarde, forçamo-las para que aprendam a levar em conta outrem, a respeitar os costumes, as conveniências, forçamo-las ao trabalho" (DURKHEIM, 2007 [1895], p. 6). Para o pai da Sociologia francesa, cada sociedade determina os meios pelos quais a educação é realizada, pois ela só pode existir se seus membros forem os mais homogêneos possíveis, e é a educação que "[...] perpetua e fortalece esta homogeneidade gravando previamente na alma da criança as semelhanças essenciais exigidas pela vida coletiva" (DURKHEIM, 2011 [1922], p. 53). Durkheim, então, define a educação como

[...] a ação exercida pelas gerações adultas sobre aquelas que ainda não estão maturas para a vida social. Ela tem como objetivo suscitar e desenvolver na criança um certo número de estados físicos, intelectuais e morais exigidos tanto pelo conjunto da sociedade política quanto pelo meio específico ao qual ela está destinada em particular (DURKHEIM, 2011 [1922], p. 53-54).

Desse modo, a educação, segundo Durkheim (2011 [1922], p. 75), é uma “[...] ação exercida nas crianças pelos pais e professores. Esta ação é constante e geral”. Constante, pois se alastra por um longo período da vida até que o indivíduo se encontre integrado à coletividade. Geral, no sentido de que se estende, indistintamente, a todas as crianças de uma dada sociedade. Desse ponto de vista, a socialização é concebida como um processo de assimilação dos indivíduos ao corpo social. Nos termos de Dubet (1996, p. 23), a socialização nada mais é do que “[...] uma subjetivação que gera [no indivíduo] o domínio de si e a autonomia. O ator é 
definido [...] pela interiorização da sociedade". Dessa forma, a educação é o processo de inculcação, de interiorização do social no próprio indivíduo.

Essa conceituação da socialização tem implicações teóricas importantes para a definição da função social da educação, que, segundo Durkheim (2011 [1922]), se conforma como uma socialização metódica e sistemática, intencional e programada das gerações mais novas. $\mathrm{O}$ autor afirma que a cada nova geração que surge "[...] a sociedade se encontra em presença de uma tábula quase rasa à qual ela deve construir novamente. É preciso que, pelos meios mais rápidos, ela substitua o ser egoísta e associal que acaba de nascer por um outro capaz de levar uma vida moral e social" (DURKHEIM, 2011 [1922], p. 55).

A emergência das instituições de Educação Infantil em nosso país, a partir do final do século passado, evidencia elementos conceituais que nos consentem ponderar sobre o alcance da socialização em termos de imposição moral do corpo social. Se, por um lado, a instituição de Educação infantil é um espaço educativo em que pesa a dimensão integradora - embora não exclusivamente -, sua função social consiste em oferecer um conjunto de experiências e de conhecimentos que se articulam ao objetivo de contribuir para a formação básica dos indivíduos em nossa sociedade. Entretanto, por outro lado, não é possível desconsiderar que, em sua organização cotidiana, diferentes formas de ação social das crianças - em especial, as brincadeiras e demais interações (com os adultos e com os pares) - são vistas como condição sine qua non para a organização de novas experiências educacionais no interior de creches e de pré-escolas que objetivam ampliar e potencializar o desenvolvimento das crianças.

As instituições de Educação Infantil são contextos educacionais fortemente marcados por uma "ação intencional" que delimita as experiências das crianças. As ações intencionalmente desenvolvidas em creches e pré-escolas são regidas por um conjunto de normas e produzem uma série de constrangimentos muito semelhantes àqueles " [...] típicos das organizações totais, com fortes limites de tempos, espaços e materiais, mas que, simultaneamente, também apresenta um conjunto de possibilidades, sobretudo de ação social, próprias da vida em coletivo" (ROCHA; BUSS-SIMÃO, 2018, p. 31).

Nesse sentido, por mais coercitivas que sejam as práticas pedagógicas e as linguagens com as quais as crianças se defrontam no cotidiano da Educação Infantil, não lhes são apresentadas de forma rígida (posto que não denotem uma prática totalmente escolarizada), possibilitando que meninos e meninas ajam no contexto dos cuidados e da educação a eles/as destinados/as. Desse modo, se, por um lado, a instituição de Educação Infantil possui uma dimensão integradora marcada por um conjunto de ritos e situações cujo propósito é inserir as crianças no universo da escolarização; por outro, meninos e meninas podem vivenciar a 
experiência educativa na instituição de Educação Infantil de modo pleno, desde que devidamente planejadas com base nas interações e nas brincadeiras que vivenciam na companhia dos pares e dos adultos (professores), tal como previsto pelas Diretrizes Curriculares Nacionais para a Educação Infantil - Resolução No 5, de 17 de dezembro de 2009 (BRASIL, 2009).

Diante disso, conceber a socialização como um processo pelo qual a sociedade age coercitivamente, isto é, considerando apenas como ela se impõe unilateralmente de modo a integrar os indivíduos às coletividades, já não faz muito sentido (ABRANTES, 2011), principalmente com a inserção, cada vez mais cedo, das crianças em contextos de vida coletiva que nossa sociedade nomeou como instituições de Educação Infantil, expressão inaugurada pela LDBEN N 9.394/1996 (BRASIL, 1996).

\section{A socialização entre as instituições que dela se ocupam}

É preciso uma aldeia inteira para educar uma criança. Provérbio africano

Outra tradição teórica, tributária do pensamento sociológico clássico e muito difundida entre pesquisadores e intelectuais do campo educacional, concebe a socialização pela sua extensão temporal (e pelo olhar das instituições que dela, historicamente, se ocuparam). Nessa perspectiva, a socialização foi dividida em dois processos distintos e subsequentes: a socialização primária e a socialização secundária (BERGER; LUCKMAN, 2004 [1966]; BERGER; BERGER, 2008 [1975]).

Berger e Luckman (2004 [1966]), dentro da proposta de construir uma sociologia do Conhecimento, compreendem a socialização como o processo ontogenético de inserção - ampla e consistente - de um indivíduo ao corpo de uma sociedade ou de um domínio dela. Esses autores a definem como um processo constituído de dois momentos específicos e ulteriores. Segundo eles:

\footnotetext{
A socialização primária é a primeira socialização que o indivíduo experimenta na infância, e em virtude da qual torna-se membro da sociedade. A socialização secundária é qualquer processo subsequente que introduz um indivíduo já socializado em novos setores do mundo objetivo de sua sociedade (BERGER; LUCKMAN, 2004 [1966], p. 175).
}

Nesse processo, os sujeitos vivem uma série de situações por meio das quais passam a se integrar à sociedade. De acordo com os autores, a socialização primária é a que insere o indivíduo, nesse caso a criança, na vida em sociedade, tornando-o, inicialmente, membro de uma família, em seguida de uma região e de uma cidade. As pessoas encarregadas de realizar 
essa primeira fase da socialização configuram-se como os outros significativos, os quais são responsáveis pela transmissão de processos subjetivos que serão apreendidos pelo indivíduo “[...] e cuja compreensão do mundo passam a se constituir no próprio mundo desse ser que acaba de chegar" (SILVA, 2008, p. 67).

Berger e Berger (2008 [1975]) explicam que a definição de outros significativos foi construída por George Herbert Mead para nomear as pessoas que possuem maior frequência de interação com a criança. Segundo os autores:

\begin{abstract}
Mead designou os grandes protagonistas do drama da socialização como os outros significativos. São as pessoas que com maior frequência se tornam objeto da interação da criança, com os quais mantém relações emocionais mais intensas e cujas atitudes assumem importância crucial na situação em que se encontra. (BERGER; BERGER, 2008 [1975], p. 176, grifo dos autores).
\end{abstract}

Por meio do conceito de outro significativo, percebe-se que a socialização primária acontece em conjunturas impregnadas de fortes ligações emocionais. Os outros significativos, por serem os sujeitos mais próximos da criança (os que mais interagem com ela), são apontados como os responsáveis por promover e desenvolver aprendizagens provenientes de sua relação com o mundo, com os outros, quanto consigo mesmas. De acordo com Berger e Luckman (2004 [1966], p. 176), “[...] a criança identifica-se com os outros significativos por uma multiplicidade de modos emocionais. Quaisquer que sejam, a interiorização só se realiza quando há identificação. A criança absorve os papéis e as atitudes dos outros significativos, isto é, interioriza-os, tornando-os seus".

À medida que a socialização avança, a criança passa a perceber que essas atitudes e esses papéis se articulam com uma realidade mais ampla. Assim sendo, “[...] nessa altura a criança passa a relacionar-se não apenas com determinados outros significativos, mas com um outro generalizado (temos aqui mais uma expressão meadiana) que representa a sociedade em geral" (BERGER; BERGER, 2008 [1976], p. 176, grifo dos autores).

Berger e Luckmann (2004 [1966]) alegam que a socialização primária encerra na medida em que a ideia de outro generalizado, em outros termos, a sociedade, se forma na consciência dos indivíduos e, desse modo, dá lugar à socialização secundária, que deriva da divisão do trabalho e que se configura como um conjunto de processos de socialização secundários, responsáveis pela inserção do indivíduo em outros setores institucionais.

Na abordagem da socialização de Berger e Luckman, há uma grande ênfase em relação à socialização primária, haja vista que seus processos ulteriores (que constituem a socialização secundária) dela dependem. Observa-se, nesse enfoque, uma evidente vinculação da socialização secundária à socialização primária, haja vista que ela é um processo subsequente 
de introdução de um indivíduo previamente socializado (em âmbito familiar) em diferentes setores da vida social.

Embora a definição de socialização primária dê a devida importância a essa fase da socialização, a inserção das crianças em espaços públicos de Educação Infantil traz implicações importantes para se reavaliar essa definição (SILVA, 2008). Dado que a presença do outro significativo é comumente associada aos entes familiares, a questão da socialização primária urge ser revista, pois “[...] a introdução precoce da criança no mundo institucionalizado transforma a socialização primária, inserindo-a no universo público, por meio das instituições destinadas à educação infantil” (SILVA, 2008, p. 68).

Para Barbosa (2007), até a metade do século passado, a socialização das crianças ocorria quase restritamente no âmbito familiar, embora alguns poucos estudos pontuais desse período demonstrassem a relevância do grupo de pares nesse processo ${ }^{2}$. Na contemporaneidade, as sociedades, no entanto, são extremamente diferenciadas e dispõem de condições muitas vezes insuficientes de estabilidade nos seus procedimentos de socialização. É preciso considerar que, na atualidade, os atores são socializados, desde a mais tenra idade, simultaneamente, por distintas instituições como a família, as instituições de educação infantil, a mídia e em relação direta com diferentes sujeitos (pais, professores, outras crianças); dessa forma, as crianças confrontam processos socializadores cada vez mais distintos, às vezes concorrentes e até contraditórios.

Além disso, como dito anteriormente, a emergência de um novo marco regulatório - que surge com a promulgação da Constituição Federal de 1988 (BRASIL, 1988) e com a nova LDBEN N 9.394/96 (BRASIL, 1996) - creches e pré-escolas (agora consideradas instituições educacionais) são reconhecidas e legitimadas, em nosso país, como primeira etapa da Educação Básica. Na visão de Cury (1998, p. 11), a novidade instaurada pela Constituição de 1988 consistia na apropriação de duas mudanças significativas em nossa compreensão social sobre a Educação Infantil: a primeira, relativa ao atendimento à criança pequena, incorporou creches e pré-escolas ao campo educacional não sob a forma da assistência e do amparo, mas sob a forma do direito das crianças e de suas respectivas famílias; a segunda transformação pressupunha que, ao Estado (compreendido como o outro generalizado), não mais seria atribuída a figura do cuidado, mas, sim, do dever que, desde então, passa a partilhar com as famílias (instituição que abarca os outros significativos) a responsabilidade sobre a educação e os cuidados das crianças de até seis anos de idade.

Assim, a presença das crianças e dos bebês em espaços coletivos de educação e de cuidado retira da socialização secundária a dependência direta da etapa anterior (socialização 
primária), haja vista que coloca meninos e meninas de até seis anos em contato direto com o outro generalizado (o Estado), que passa a dividir com os outros significativos (a família) a tarefa de socialização dos/as pequenos/as.

\title{
Olhares contemporâneos que subvertem o conceito clássico de socialização
}

\author{
Por que que a gente espirra? Por que as unhas \\ crescem? Por que o sangue corre? Por que que a gente \\ morre? Do que é feita a nuvem? Do que é feita a neve? \\ Como é que se escreve Re...vèi...llon \\ Paula Toller (OITO anos, 1998, n.p.)
}

Suzanne Mollo-Bouvier (2005), socióloga da infância francesa, ao analisar as influências das transformações do ambiente familiar das crianças nos processos de socialização dos quais elas participam, assegura que esse conceito não deve ser tomado em sentido clássico, ou seja, na acepção de Durkheim (2011 [1922]), que o concebia como um processo de identificação e integração dos indivíduos ao sistema. Para ela, deve ser tomado em uma "[...] perspectiva interacionista que salienta a dinâmica das interações na aquisição de know-hows e insiste no vínculo entre conhecimento de si e conhecimento do outro, construção de si e construção do outro" (MOLLO-BOUVIER, 2005, p. 392), o que denota uma participação mais ativa e reflexiva das crianças nos próprios processos de socialização.

Crítica similar é realizada por autores do campo da Sociologia da Educação contemporânea. Araújo e Martuccelli (2010), por exemplo, asseguram que, com a emergência dos indivíduos no âmbito das análises sociológicas atuais, as teorias clássicas da socialização apresentam um considerável número de insuficiências que convidam os cientistas sociais a utilizar outras estratégias capazes de descrever o trabalho do indivíduo para fabricar-se como sujeito. Nesse sentido, a socialização perde sua centralidade na produção e na inserção de indivíduos no âmbito social. De acordo com os autores:

\begin{abstract}
A socialização não é a única maneira de se conceber o processo de fabricação dos indivíduos. Próximo a ela é possível distinguir pelo menos duas estratégias principais: a subjetivação e a individuação. Esquematicamente, a socialização estuda o processo de fabricação sócio psicológica dos indivíduos; a subjetivação aborda, no contexto da sociologia, o problema da constituição do sujeito como resultado das dinâmicas sociopolíticas de emancipação; a individuação se interessa, a partir de uma perspectiva sócio histórica, pelo tipo de pessoa que está sendo estruturalmente fabricado em uma sociedade. (ARAÚJO; MARTUCCELLI, 2010, p. 79).
\end{abstract}

Araújo e Martuccelli (2010) ainda afirmam, na perspectiva clássica, que eram os processos de socialização que garantiam a estreita conexão entre as expectativas pessoais e possibilidades objetivas, pois o processo de fabricação dos indivíduos, graças à socialização, proporcionava um progressivo ajuste e garantia à adequação do indivíduo à sociedade. 
$\mathrm{Na}$ atualidade, os atores veem-se frente a um conjunto cada vez mais amplo e heterogêneo de indivíduos e instituições e são afetados com uma intensidade cada vez maior por estímulos do ambiente que resultam em uma "[...] pluralidade de sistemas de ação regidos por orientações e regras cada vez mais autônomas" (DUBET; MARTUCCELLI, 1997, p. 244), o que obriga o sujeito a produzir um sentido próprio de sua experiência, a partir de sua capacidade de articular vários registros de ação (DUBET, 1996). Dito de outro modo, a socialização resulta de uma série cada vez mais contingente e diversificada de experiências produzidas pelos próprios indivíduos no decurso de suas vidas. Essa assertiva permite-nos afirmar que a socialização da criança na contemporaneidade ocorre a partir de uma noção interativa que leva em conta a capacidade de ação de meninos e de meninas, mas que não se dá de forma linear, pois é marcada por descontinuidades e rupturas. Assim, percebe-se que:

A socialização compõe-se de dessocializações e ressocializações sucessivas. Ela é a
conquista nunca alcançada de um equilíbrio cuja precariedade garante o dinamismo.
Em contrapartida, essa concepção interacionista da noção de socialização implica que
se leve em conta a criança como sujeito social, que participa de sua própria
socialização, assim como da reprodução e da transformação da sociedade. (MOLLO-
BOUVIER, 2005, p. 393).

Exemplo dessa abordagem interacionista da socialização é encontrado na obra do sociólogo da infância estadunidense Willian Corsaro (1997). Esse autor afirma que, ao interagirem entre si, as crianças vão se apropriando de modo interpretativo de informações do mundo adulto, que são articuladas em um processo de elaboração simbólica peculiar pelo qual ocorre uma aprendizagem social. Dito de outro modo, a partir das aprendizagens decorrentes das relações intergeracionais e intrageracionais, isto é, entre crianças e adultos e entre elas, meninos e meninas não se colocam passivamente; pelo contrário, assumem uma postura notavelmente interativa, pois, principalmente nas relações com os pares, as crianças aprendem umas com as outras, nos ambientes sociais que partilham em comum, constituindo, desse modo, culturas de pares (CORSARO, 1997).

Corsaro (2009) entende que as crianças assimilam criativa e interpretativamente os elementos do universo cultural adulto (por meio de um fecundo exercício relacional e dialógico), por meio do qual produzem culturas particulares e únicas. Para o autor, as culturas de pares conformam "[...] um conjunto de atividades ou rotinas, artefatos, valores e preocupações que as crianças produzem e partilham na interação com os seus pares" (CORSARO, 2009, p. 32).

O pesquisador afirma que as evoluções recentes do campo da Sociologia da Infância conduziram-no a desenvolver uma abordagem interpretativa da socialização infantil que a 
considera mais um processo reprodutivo do que linear, portanto, mais interativo, isto é, mais relacional do que passivo. Trata-se da reprodução interpretativa (CORSARO, 1997) da cultura na qual a expressão "interpretativa” compreende as peculiaridades da participação das crianças na sociedade, sugerindo que elas criam e compartilham formas de produção simbólica a partir da apropriação de informações do mundo adulto de modo a atender interesses próprios de uma criança ou do grupo. Já a expressão "reprodução" sugere que as crianças não apenas absorvem a cultura, mas contribuem de forma ativa tanto para a produção quanto para a transformação social (CORSARO, 1997).

As crianças são consideradas seres sociais imersos, desde cedo, em uma rede social já estabelecida e, por meio do desenvolvimento da comunicação e da linguagem - fatores que permitem uma maior interação com os outros - constroem seus mundos sociais. Associando isso ao alargamento de seu contexto de interações sociais ${ }^{3}$, as crianças ampliam suas possibilidades de assimilar o mundo que as rodeia, expandindo, assim, as culturas de pares e reconstruindo a cultura adulta (CORSARO, 2002, p. 114).

No caso específico das instituições de Educação Infantil, ainda que pese a dimensão integradora (que abarca um conjunto de situações que objetiva a progressiva inserção de meninos e de meninas na vida social), o reconhecimento de tais formas de ação das crianças torna possível e desejável que elas façam escolhas que as permitam conduzir alguns dos processos de socialização. De igual modo, não é possível desconsiderar que o entrecruzar de diferentes processos socializadores advindos de diferentes instituições (mídia, famílias, grupos de crianças), no contexto da Educação Infantil, pressupõe descontinuidades e rupturas e precisa ser visto como possibilidade real de desenvolvimento. Dito de outro modo: é essa articulação de lógicas (ora conflitantes, ora concorrentes) que nos permite falar de ampliação de experiências no contexto da Educação Infantil, entendendo-as como o engajamento das crianças em um trabalho de socialização sobre si mesmas (DUBET, 1996).

\section{Considerações finais}

Compreende-se, por fim, que essa articulação entre distintos sujeitos e diferentes instituições conduz as crianças a articularem variadas possibilidades e formas de registro de suas ações nos próprios processos de socialização dos quais participam no contexto da Educação Infantil. Trata-se, desse modo, de reconhecer a socialização como um complexo conjunto de processos socializadores, no qual a criança interage com os adultos, com seus pares, com a cultura e a sociedade. Como dito anteriormente, o intercruzar desses processos muitas 
vezes proporcionam avanços e retrocessos, isto é, sucessivas dessocializações e ressocializações (MOLO-BOVIER, 2005), não ocorrendo de modo linear e unilateral. Nesse sentido, a instituição de Educação Infantil, para além de se constituir como um espaço de educação e cuidado, assume a dupla tarefa de se configurar tanto como espaço de socialização quanto lócus de produção de experiências sociais, no qual as crianças desenvolvem-se integralmente, respondendo suas inquietações pessoais (tal como Gabriel, eu lírico da canção de Paula Toller que abre este texto) e tendo, portanto, a garantia de viver a infância. 


\footnotetext{
${ }^{1}$ Este ensaio é uma versão ampliada e revista de parte do capítulo teórico de minha tese de doutoramento intitulada: Socialização de gênero na Educação Infantil: uma análise a partir da perspectiva das crianças, defendida em outubro de 2016, no Programa de Pós-Graduação Conhecimento e Inclusão Social da Faculdade de Educação da Universidade Federal de Minas Gerais (UFMG), sob a orientação de Isabel de Oliveira e Silva, a quem agradeço imensamente. Igualmente, agradeço à Coordenação de Aperfeiçoamento de Pessoal de Nível Superior (Capes) pelo apoio financeiro.

2 Importante destacar que essa proposição deriva de uma crítica interna à própria Sociologia, realizada por representantes de diferentes subdisciplinas (Sociologia da Educação, Sociologia da Família, Sociologia da Infância, dentre outras) e que é dirigida às versões "clássicas" do conceito de socialização, que persistem, ainda hoje, em diferentes tradições teóricas.

${ }^{3}$ Como, por exemplo, o estudo realizado por Florestan Fernandes entre os anos de 1940 e 1950, intitulado As trocinhas do Bom Retiro, que evidencia a capacidade de as crianças ressignificarem elementos da cultura adulta, incorporando-os às brincadeiras dos grupos vicinais, contribuindo, desse modo, para a produção e a reprodução social (SANTOS, 2014).

${ }^{4}$ Como, por exemplo, a transferência da criança do meio familiar para um contexto educacional institucionalizado.
}

\section{Referências}

ABRANTES, P. Para uma teoria da socialização. Sociologia: Revista da Faculdade de Letras da Universidade do Porto, Porto, v. XXI, p. 121-139, 2011.

ARAUJO, K.; MARTUCCELLI, D. La individuación y el trabajo de los indivíduos. Educação e Pesquisa, São Paulo, v. 36, n. especial, p. 77-91, 2010.

BARBOSA, M. C. Culturas escolares, culturas de infância e culturas familiares: as socializações e a escolarização no entretecer destas culturas. Educação \& Sociedade, Campinas, v. 28, n. 100, p. 1059-1083, 2007.

BERGER, P.; BERGER, B. Socialização: como ser um membro da sociedade. In: FORACHI, M. M.; MARTINS, J. S. (org.). Sociologia e sociedade: leituras de introdução à sociologia. Rio de Janeiro: LTC, 2008 [1975]). p. 169-181.

BERGER, P.; LUCKMANN, T. A Construção Social da Realidade. Tradução de Floriano de Souza Fernandes. Petrópolis: Vozes, 2004 [1966].

BRASIL. [Constituição (1988)]. Constituição da República Federativa do Brasil. Brasília, DF: Senado, 1988.

BRASIL. Lei No 9.394, de 20 de dezembro de 1996. Estabelece as diretrizes e bases da educação nacional. Diário Oficial da União: seção 1, Brasília, DF, n. 248, p. 27833-27841, 23 dez. 1996.

BRASIL. Resolução No 5, de 17 de dezembro de 2009. Fixa as Diretrizes Curriculares Nacionais para a Educação Infantil. Diário Oficial da União: seção 1, Brasília, DF, n. 242, p. 18-19, 18 dez. 2009.

CORSARO, W. A. The sociology of childhood. Califórnia: Pine Forge, 1997.

CORSARO, W. A. A reprodução interpretativa no brincar ao "faz de conta" das crianças. Educação Sociedade \& Culturas, Porto, n. 17, p. 113-134, 2002. 
CORSARO, W. A. Reprodução Interpretativa e Cultura de Pares. In: MÜLLER, F.;

CARVALHO, A. M. A. (orgs.). Teoria e prática na pesquisa com crianças: Diálogos com William Corsaro. São Paulo: Cortez, 2009. p. 31-50.

CURY, C. R. J. A Educação Infantil como Direito. In: BRASIL. Subsídios para o credenciamento e funcionamento de instituições de educação infantil. Brasília: MEC, 1998. p. 9-15.

DUBAR, C. A Socialização: construção das identidades sociais e profissionais. São Paulo: Martins Fontes, 2005.

DUBET, F. Sociologia da experiência. Lisboa: Instituto Piaget, 1996.

DUBET, F.; MARTUCCELLI, D. A socialização e a formação escolar. Lua Nova, São Paulo, n. 41, p. 241-328, ago. 1997.

DURKHEIM, D. E. As regras do método sociológico. Tradução de Paulo Neves; revisão de Eduardo Brandão. 3. ed. São Paulo: Martins Fontes, 2007 [1895]. (Coleção Tópicos).

DURKHEIM, D. E. Educação e Sociologia. Tradução de Stephania Matousek. Petrópolis, RJ: Vozes, 2011 [1922]. (Coleção Textos fundantes de Educação).

JENKS, C. Constituindo a Criança. Educação, Sociedade \& Culturas, Porto, n. 17, p. 185$215,2002$.

MARCHI, R. C. As Teorias da socialização e o novo paradigma para os Estudos Sociais da Infância. Educação \& Realidade, Porto Alegre, v. 34, n. 1, p. 227-246, jan./abr. 2009.

MOLLO-BOUVIER, S. Transformação dos modos de socialização das crianças: uma abordagem sociológica. Educação \& Sociedade, Campinas, v. 26, n. 91, p. 391-403, 2005.

MONTANDON, C. Sociologia da Infância: balanço dos trabalhos em língua inglesa. Cadernos de Pesquisa, São Paulo, n. 112, p. 33-60, mar. 2001.

OITO anos. Intérprete: Paula Toller. Compositores: Paula Toller e Dunga. In: PAULA Toller. Intérprete: Paula Toller. Rio de Janeiro: Warner Music Brasil, 1998. 1 CD, faixa 4.

PLAISANCE, E. Para uma sociologia da pequena infância. Educação \& Sociedade, Campinas, v. 25, n. 86, p. 221-241, abr. 2005.

PLAISANCE, E. Socialização: modelo de inclusão ou modelo de interação? Revista PerCursos, Florianópolis, v. 4, n. 1, p. 1-15, 2003.

QVORTRUP, J. Nove teses sobre a "infância como um fenômeno social". Pro-Posições, Campinas, v. 22, n. 1 (64), p. 199-211, jan./abr. 2011.

ROCHA, E. A. C.; BUSS-SIMÃO, M. Infância, experiência e educação: apontamentos a partir de reflexões sobre a pequena infância. Childhood \& Philosophy, Rio de Janeiro, v. 14, n. 29, p. 27-42, 2018. DOI: 10.12957/childphilo.2018.30577 
SANTOS, S. V. S. dos. Crianças e Educação Infantil: ampliação e continuidade das experiências infantis em contextos de cuidado e educação. Jundiaí: Paco Editorial, 2015.

SANTOS, S. V. S. Sociologia da infância: aproximações entre Willian Corsaro e Florestan Fernandes. Educação em Perspectiva, Viçosa, v. 5, n. 1, p. 117-139, jan./jun. 2014.

SARMENTO, M. J. Sociologia da Infância: correntes e confluências. In: SARMENTO, M. J.; GOUVEA, M. C. S. (orgs.). Estudos da infância: educação e práticas sociais. Petrópolis: Vozes, 2008. p. 17-39.

SILVA, I. O. Educação Infantil no coração da cidade. São Paulo: Cortez, 2008.

SINGLY, F. Sociologia da família contemporânea. Tradução de Clarice Ehlers Peixoto. Rio de Janeiro: Editora da FGV, 2007.

SIROTA, R. Emergência de uma sociologia da infância: evolução do objeto e do olhar. Cadernos de Pesquisa, São Paulo, n. 112, p. 7-31, mar. 2001.

VIEIRA, L. M. F. Creches no Brasil: de mal necessário a lugar de compensar carências rumo à construção de um projeto educativo. 1986. 347 f. Dissertação (Mestrado em Educação) Universidade Federal de Minas Gerais, Belo Horizonte, 1986.

WARTOFSKI, M. The child's construction of the world and world's construction of the child: From historical Epistemology to historical Psychology. In: KESSEL, F. S.; SIEGEL, A. W. (Eds.) The child and other cultural invenctions. New York: Praeger, 1981. p. 191-214. 